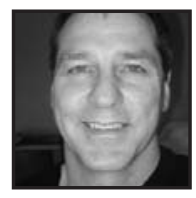

\title{
Hospitality and the Hôte: Revealing Responsibility Through Found Poetry
}

Tim Molnar, University of Saskatchewan

\section{ABSTRACT}

This work provides insight into the experience of a group of Aboriginal and nonAboriginal educators and their sense of responsibility. This involves discussions concerning the use of found poetry as well as how found poetry aided in fashioning an interpretation of educator's experience of the hôte: a guest-host who accommodates and negotiates the difference of others and self.

\section{The Hôte}

Who did I want to be and need to be credible to?

What kind of Indian was I to give up the sacred place for children?

Saying that out loud sounds bizarre Being half and half - it's always a tension Damned if you do and damned if you don't

What did I do first? Panicked! I was lost

It was supposed to be

'Everybody showed up - I taught - we left They came back homework done - We went on to the next thing' That doesn't happen!

Kids will ask me if I am Métis

They think maybe I belong - I tell them I am not

It was really bizarre because I wanted to say, 'Yes!' I wanted them to go 'She fits' 
I would go home after school and say something to my spouse And they look at me and say, 'Who are you?'

Well I don't know! I have been here long enough I have soaked it all in

I had finally started to be considered an insider The kids were calling me Kokum

I know I truly don't truly ever completely belong Inclusion will be extended to me or not When it is extended to me I feel like I belong Not as an equal but as a respected part... I don't know how to explain what I am saying

I can be a First Nations and still wonder,

'Is it my job to be doing it or is it an Elder's job?'

You have such a variety within the First Nations Traditional, Christian, a few that really don't bother I really have to watch I can't force them to believe or to value the things that I do I try to speak to it as a person, as a human you know As First Nation's people we have to fit into society I know Nothing has really changed only they have put us in their spots

We are really doing it to ourselves We are doing their work for them now and they have made us... I shouldn't say 'they'! It's like who are 'they'?

\section{Introduction}

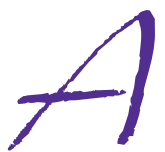

s I look over the poem "Hôte," composed from the words of several of my former teaching colleagues, I remain captivated by the strained sensibility evident concerning identity, role and responsibility. These four people, whose words comprise this poem, some of Aboriginal and some of non-Aboriginal heritage, were teachers I worked closely with for several years. We worked in an innercity school in Western Canada, with a small student population of around 200 students, mostly of First Nation heritage. These students faced the typical academic challenges and pursuits of those in a high school, but also frequently dealt with 
circumstances in their lives involving death and violence, and socioeconomic challenges such as poverty and transience.

These teachers, along with several other educators in this school, eventually became participants in my research on responsibility-research undertaken after I left teaching in this school. This research involved a series of interviews and conversations with participants over two years, as I investigated their experience and the notion of responsibility (Molnar, 2009). Part of this process involved exploring the feasibility and suitability of the work of Emmanuel Levinas $(1961,1981)$ for understanding teachers' experience. To this end I created a theoretical framework for understanding responsibility, based on Levinas' ideas but also that of Derrida $(1999,2002)$, and Todd $(2003 c, 2007,2008)$. I employed this guide to both examine the experience of these teachers, and to gauge the helpfulness of relying on Levinas' work for understanding responsibility. Hospitality and the experience of the hôte was one of several themes I investigated through the creation of found poems.

In what follows it is not my intent to provide a detailed philosophical interpretation of responsibility and the role of the hôte, nor to extensively support my claims that Levinas' work can be helpful in understanding teachers' sense of responsibility. This writing exists elsewhere (Molnar, 2009). Neither will I suggest a method for creating found poetry. However, I will provide comment as to why and how I employed found poetry in fulfilling the dual task of crafting both interpretation and representation in research-a sharing that I hope will be helpful to the reader.

To accomplish this I offer a brief overview of found poems, my reasons for employing them, followed by a brief discussion concerning the nature of hospitality and the hôte as a way to conceive of human responsibility. These discussions give way to my reflections on the experience of crafting found poems as part of a philosophical hermeneutic or interpretation (Caputo, 1987, 2000; Gadamer, 1976; Gadamer \& Silverman, 1991), and as a way of representing the experience of research participants in support of such interpretation. I end with some thoughts concerning research and the experience of the hôte.

\section{Why Found Poetry}

During my research, while surveying various literature concerning qualitative research methodology, I happened upon the use of found poetry. Here I found 
writers such as Richardson $(1994,2003)$ and Sparkes (2002) suggesting poetry was a meaningful way to provide insight into the words of others or oneself that had a place in research. They suggested poetry is helpful in re-telling "experiences in such a way that others can experience and feel them" (Richardson, 2003, p. 197) and in a manner invite the reader "into the interpretive realm where the writer (and the reader) make leaps" (Sparkes, 2002, p. 116) or connections in meaning. Such representation also seemed useful in being similar to how people actually talked and conveyed meaning (Richardson, 2003), which allowed further accessibility for readers to the intended meaning and lived experience of others. What might be a third argument for their use involved giving the reader an alert "that it is the author who is staging and shaping the text" (Sparkes, 2002, p. 116), and in this realization readers can recognize the writer is offering a singular interpretation among many possible interpretations. This, if we believe Gadamer $(1976 ; 1991)$ and Caputo $(1987,2000)$, acts as a healthy guard to any attempt to claim absolute truth in regards to human understanding, a perspective that may actually subvert what utility and meaning we may gain from a text.

Despite such supporting literature, one can still ask why they were meaningful for my work. My larger research piece, of which investigating hospitality was only a portion, was an exploration concerning the feasibility of employing a particular philosophy to understand responsibility. However, my interpretive efforts often involved intuition as much as reasoning and I find it difficult to separate the rational and intuitive in responding to the question I just posed.

However, given that my philosophical investigation involved exploring the very intimate experience of responsibility, I felt a need to reduce the emotive distance there may be between participants and readers - a distance perpetuated perhaps, given the more technical and analytical approach to interpretation that typified other parts of my research. Like Steffler (1995), I desired "through the convenient portability of words" to offer a "semblance of direct experience, a recovery or approximation of emotional experience that engages our sense of the numinous and the aesthetic" (p. 49). My research participants were more than convenient and knowledgeable individuals to talk with, but had been supportive colleagues and friends, who shared their lives, hopes and aspirations with me intimately, and to whom, in a most Levinasian manner, l owed a debt-a debt not merely for their participation, but because of their humanity. I sympathized and empathized with their efforts, their dignity and their desire for the best for their students. Through the use of poetry I hoped to more fully honour and respect the words and presence of these people, to provide a fuller sense of their struggle and thoughts. I desired to accurately portray 
the uncertainty and questioning nature in their sense of responsibility, as they struggled to aid their students, and each other, amid the frequently daunting challenges of their work.

The choice to craft poetry also emerged from my creative urges; these were ever at play as I read and considered the words of participants and various interpretations and presentations for conveying meaning. There is something about poetry that pushes, as Leggo (2006) notes, "at the edges, sometimes even extending beyond the edges, even to the places where language refuses, comprehensibility, clarity, coherence..." (p. 89), and with the use of poetry I hoped readers might also push beyond the edges of a casual consideration of peoples' experience.

The processes of interpretation and creating poetry seemed to compliment and support each other and resonated with my sense of research as artful, intuitive and spontaneous - as an endeavor involving connoisseurship and judgment (Eisner, 1991; Eisner \& Peshkin, 1990).

This is a partial response as to why l employed found poetry, there is still left to consider, how this approach works itself out in the context of a theme such as hospitality. Therefore, the following section discusses briefly the notion of responsibility as hospitality, a discussion that will help in considering the suitability and resonance of "The Hôte" and positions us to examine further the challenges I encountered in employing found poetry.

\section{Responsibility as Hospitality}

In considering the experience of teaching amid the tensions of ethno-cultural difference, ideas of community, communing and belonging evolved into an interest concerning the nature of responsibility. This led me to explore Levinas' philosophy of the Other (Levinas, 1961, 1981), a journey involving related work by Jacque Derrida $(1999,2002)$ and Sharon Todd (2003b, 2003c, 2008). Fashioning a philosophical interpretation of responsibility I realized the experience of hospitality might be potentially helpful in understanding the experience of participants. There was, however, a particular aspect of hospitality that seemed especially meaningful. This was the idea, sensibility and experience of the hôte. 


\section{Hospitality and the Hôte}

Levinas talks of responsibility as a welcoming, and Derrida in turn discusses hospitality as a feature of such welcoming. But what do they mean by this? Derrida, in speaking of hospitality, is alerting us to a deeper reality concerning our encounter with others as he explains,

The word "hospitality" here translates, brings to the fore, re-produces...a sort of periphrasis, a series of metonymies that bespeak hospitality, the face, welcome; tending toward the other, attentive intention, yes to the other. Intentionality, attention to speech, welcome of the face, hospitality-all these are the same as the welcoming of the other, there where the other withdraws from the theme. (1999, p. 22)

In other words, responsibility involves an encounter that is typified by an attentiveness to, and accommodation of, what is the infinite and ultimately unknowable difference of other human beings. This involves a person's enactment and embodiment as a host who "knows what it means to be at home, and that at home one receives, invites, or offers hospitality, thus appropriating for oneself a place to welcome [accueillir] the other" (Derrida, 1999, pp. 15-16), but simultaneously finds themselves a guest in their own home or circumstance, changing to accommodate others. In other words, the experience of hospitality involves the sensibility of no longer being at ease and certain in one's home. This, as Derrida suggests, is where "the head of the household, the master of the house, is already a received hôte, already a guest in his own home" (1999, p. 42). What exists here is the

implacable law of hospitality: the hôte who receives (the host), the one who welcomes the invited or received hôte (the guest), the welcoming hôte who considers himself [sic] the owner of the place, is in truth a hôte received in his [sic] own home. He receives the hospitality that he offers in his own home; he receives it from his own home-which, in the end, does not belong to him. The hôte as host is a guest. (Derrida, 1999, p. 41)

What does Derrida mean by this? Derrida is not merely referring to the simple courtesy of inviting another into one's physical home but how the difference of others is welcomed and accommodated by us, found active within ourselves, residing within our psyche, existing alongside and altering our identity. This situation is not one of ease but is typified by uncertainty, ambiguity and questioning. 
I found myself facing the challenge of seeking out this sensibility in the words of participants. Providing quotes from participants in the manner of a more traditional argument would help substantiate my interpretation but I wondered if there was a way to present the sensibility of the hôte in a manner that conveyed the commonality of participants, yet revealed their diversity and difference as individuals.

In what follows I provide some explanation concerning how I crafted the found poems in my work, the process that emerged in terms of interpretation and presentation, and the challenges I encountered. In other words, I address the question, "What were the processes and challenges in using found poetry, what was it like and what did it mean for you?" A discussion of the structure of "The Hôte" seems a convenient starting place for beginning such a discussion, so I will begin there.

\section{Crafting Found Poems: Structure, Process and Challenge}

\section{Structure}

The poem "The Hôte" contains four sections fashioned from my conversations with four teachers. An initial reading of this poem may leave one unsure of who is talking for I offer no descriptions or background to the speakers, however a careful reading reveals that two of these individuals are of Aboriginal heritage, while the others are not. I crafted the poem to present four voices that were unique, yet similar in experiencing the uncertainty and unease of the hôte.

The structure of the poem attempts an interplay or movement between question and answer, description and explanation, and consideration and reconsideration. Such structuring was both an intended and unintended out come of working with the words of participants, and emerged both from the way conversations with participants flowed, but also from my efforts to craft the words of participants to reveal poignant and meaningful moments of the hôte.

In each section of the poem and in the poem as a whole, lines on the left and above lead to those on the right and below, from non-italicized text to italicized; a modification offered with the hope of alerting readers to a transition in who is "speaking" and signaling a shift in the thinking and emotion of participants. The participant conversations that gave rise to the poem were in essence critical reflections that 
carried with them a sense of unease and uncertainty concerning peoples' understandings of self, role, identity and others-a central feature of the sensibility of the hôte. Structuring the found poem in this manner was one way to illustrate important sensibilities of the hôte, such as uncertainty and unease.

While this format is obvious to the reader, and provides some coherence and poignancy to the poem, arriving at this form was not so simple, and emerged only as I revisited participants' transcripts, participants' recorded conversations and my interpretive guide; a document I will discuss below. However, another factor influenced how the poetic structure occurred. Even before crafting the "Hôte" and other poems, I had already been busy questioning, substantiating and gauging the helpfulness of Levinas', Derrida's and Todd's work and this interpretive effort involved this structure of question and response. Unsurprising perhaps, this mode of presenting found its way into"The Hôte."This structure of questioning or stating, followed by further elucidation emerged as a consistent feature in all five found poems I crafted in my research (Molnar, 2009).

In "The Hôte" there is also movement or transition that builds from strong instances of the hôte, to what I consider an exemplar of the sensibility of the hôte; an exemplar that is nuanced and extremely poignant. Here my efforts are direct and calculated as I attempt to expand on participants' sensibility of the hôte. This movement begins with Pat, who like other participants to follow in this article, I have given a fictitious name. I relied upon Pat's words to introduce and reveal the unease and uncertainty of the hôte. I knew Pat well and Pat's words held deep meaning for me, as an example of the struggle and questioning of the norm of contemporary schooling among my colleagues, especially those of First Nation heritage. In presenting Pat's thoughts such as, "What kind of Indian was I to give up the sacred place for children?" and in "Being half and half - it's always a tension" I wished to illustrate that the dilemma of role and identity is not necessarily resolved by self-identifying with an ethno-cultural group and that no matter how strong one's self identification may be, in being responsible, the experience of the hôte may exist.

Jordan, a non-Aboriginal teacher, whose encounter with students leave Jordan's spouse asking, "Who are you?" reveals again the tension of the hôte. We can again witness moments where the hôte "is not a being that always remains the same, but is the being whose existing consists in identifying itself, in recovering its identity throughout all that happens to it" (Levinas, 1961, p. 36). 
With the third speaker also non-Aboriginal, Kerry, despite feelings of belonging and inclusion with First Nations culture reveals the tension of the hôte. This sensibility is found in the discrepancy between Kerry's intellectual acceptance of difference, contrasted with a sense of emotional belonging. Kerry possesses a sense of shared identity and inclusion even while acknowledging,"I know I truly, don't truly, ever completely belong." However one chooses to employ the notions of belonging and inclusion or of identity or role, for participants such as Kerry, Pat and Jordan the tensions and contrasts of the hôte exist.

I chose the words of Blair last. Among these colleagues there is perhaps no more poignant example of the hôte than Blair's final statement. Blair's words reveal the uncertainty of a person who senses the difference of others, the "they," who must be accommodated with one's conception of self. We see with Blair, if we believe Derrida, the contending of a self with the "He [II] in the depth of You [Tu]" (1999, p. 60). Blair identifies the "they" as self even while seeking to remain part of an "us." This struggle to accommodate is a prominent feature of hospitality demonstrated by experience of the hôte.

While found poems may be presented in variety of ways, and those who employ them will craft them according to their purposes, there was on my part a very specific goal. This goal was to support and illustrate my philosophical arguments by presenting vivid instances of the hôte. Others will do differently for their needs.

In discussing the structuring of the "Hôte"I have already begun to touch on other aspects of the process of crafting found poems. The following discussion offers further insight into how this occurred.

\section{Process}

The crafting of "The Hôte" and other found poems in my research began even before I knew I would employ them. In other words, a priori to my conscious decision to employ found poetry, certain processes crucial to the development of found poems were active. In the necessity of developing the interpretation sections of my work I was already reading transcripts, listening to recorded conversations of participants, and compiling working notes. These activities, while not initially done with the crafting of found poems in mind, formed the foundation of the crafting process and were part of an evolutionary process of meaning-making involving both poems and interpretive guide. I am uncertain just how the crafting of these poems may have differed in development if I had begun my research with the use of them 
in mind. I suspect this would have yielded a different outcome in terms of presentation. In any case, these interpretive activities provided me with a nuanced meaning of participants' thought and were crucial in allowing me to identify, select and edit, cogent and poignant passages in crafting the poems.

To aid in making sense of transcripts and audio recordings I developed an interpretive framework or guide. This guide helped, not only with interpreting participants' experience, but also in judging the suitability and quality of particular passages from participants' transcripts. The guide consisted of several pages of key ideas and questions regarding hospitality, the sensibility of the hôte, and other features of responsibility. In crafting "The Hôte" I used this guide to query the participants' information, in a manner "testing" for the sense of uncertainty and discomfort of the hôte. The initial development of this guide was the result of a lengthy process over four years of reading, thinking, discussing with colleagues, and writing about the ideas of philosophers such as Levinas, Derrida and Todd. My use of this guide in tandem with crafting found poems happened in the latter part of this time frame. This guide encapsulated my understanding of responsibility, however, this document remained a work in progress and further alteration and more sophisticated renderings of this document continued to evolve.

Having such a document aided me in maintaining my interpretive focus amid the intriguing and interesting, yet distracting information that often emerges when reading and listening to the stories of others.

As I realized my desire for, and the potential benefit of crafting found poems for my research, a process of creative reciprocity emerged between my development of the guide and the poems. Though not initially conceived as a tool or method for aiding in the crafting of found poems, the interpretive guide acted as touchstone and catalyst in making judgments concerning the selections of text and how the text was presented.

In the process of selecting passages and structuring the found poems, I was continually faced with considering how well I understood the sensibility of the hôte. The urge to craft poems in a manner complimentary to my interpretations, was an impetus in developing a more acute sense of the hôte-an acuity more keen than perhaps might have arisen from my only forming and presenting a philosophical argument. With the purpose of crafting poems becoming a central feature of the presentation and introduction to my discussions of responsibility, some comments and passages from participants, initially overlooked, now took on significance while others seemed less suited for my purposes. 
My description may seem to suggest a simple application of technique, where there is the reading of a guide with the words of participants and the simple selection of pertinent passages. However, the process of composing the poems was far from a systematic, linear and lockstep procedure. While there were was a certain level of "technique" (Ellul, 1964) in crafting the found poems, no set of guidelines, processes and the like would free me from a reliance on judgment-a judgment that involved a mix of intuition, reason, an intimate understanding of Levinas' and Derrida's work, and my high degree of familiarity with participants and their experience of their school context. In my case, the crafting of found poems seemed less a matter of technique and more a matter of acting on one's judgment; where there was no right or wrong way to proceed or present, just levels of sufficiency in sharing the intended meaning of a poem and prompting readers' engagement.

While one can sense in this discussion of structure and process some of the challenges I encountered, there were particular concerns that persistently came to my attention as I crafted poems and considered these poems in relationship to my research. The following section describes some of those I faced, what I thought of them, and my attempts to resolve them.

\section{Challenges}

I faced challenges on essentially two fronts. First, there was what I would term practical and aesthetic challenges and secondly, challenges of an ethical nature. These challenges were not discrete from each other.

In the first instance, there is perhaps no surprise to be found concerning the significant time and energy required for crafting a series of found poems or even one such as "The Hôte." This involved many hours of reading transcripts, listening repeatedly to recorded conversations, rewriting my guide and assembling possible participants' quotes, before sorting selections, judging their worthiness and finally putting their words on to paper. In my case, regardless of how it played out, this commitment was unavoidable and especially so in dealing with the words of others, for if one is to be confident in the presentation of others' words, then the time and energy required to prepare and craft the poem is not only well warranted but also necessary, for both practical and ethical reasons.

There is, however, the chance that at some point this effort becomes a matter of diminishing returns. In crafting found poems, people must guard against over extending their effort, especially given a researcher's enthusiasm for their subject, for 
such over extension may easily occur and potentially hinder their overall effort. This depends of course on whether a person is crafting a single poem or many, in what context and for what purpose. Judging how far or how much one needs to go can be challenging. One remedy for this may be found in how well a researcher knows the participants in his or her research, and knows the context of these participants. In my case, an in-depth understanding of former colleagues and their teaching situation helped in building confidence and in limiting the time and energy required for crafting poems. Despite this, I admit to falling prey to reworking poems frequently, fearing that what existed was still insufficient for illustrating the sensibility being discussed and in portraying the voices and experiences of participants accurately and respectfully.

Another challenge emerged involving the philosophical "language" of Levinas (Davis, 1996; Hutchens, 2004) and even Derrida; their terminology, though instructive, was often difficult to decipher and comprehend. I wondered if my grasp of this "language" and my efforts to transpose the meaning found there, via found poems, actually portrayed the sensibilities to be discussed. To check the validity of what I was crafting and to develop further trust in my crafting abilities, at various times, I provided copies of poems to critical readers, such as teachers and scholarly colleagues and on occasion participants. Their responses aided me in assessing the worthiness and meaningfulness of the poetry.

For a time I struggled with whether using found poems as a feature presentation for evidence of the hôte would be sufficiently insightful for the reader. Would the poem alone provide enough information for people to fairly judge the validity of the interpretation offered? How detailed did the passages in the poems need to be in order to aid in the following discussion? If I offered too little would the readers be left confused and frustrated? If I offered too much detail would they become resentful or disinterested? Such questions left me considering how I would develop the relationship between poem and discussion. Initially I had planned on relying only on found poems as evidence, citing parts of them as necessary, but realized that a more powerful and well-informed interpretation, perhaps less obscure to the reader, might be rendered by including in discussions the enclosing or surrounding text from which the poems originated. Therefore, I introduced each discussion section on responsibility with a found poem using the passages of the poems to introduce an idea and then linking to the original quotations so as to expand the discussion.

Other challenges involved addressing whether there was a need to use the "voices" of all participants for each found poem, or whether to employ the voices of 
Aboriginal and non-Aboriginal participants in all poems, or only some, in what proportions, or in what order. I wondered, how was I to weave the words of various participants together and what should the length of poem be? Questions such as, "At what point was a poem no longer a poem but only a listing or collection of quotes and if my poems were the latter, what does this imply?" or "Is the trustworthiness of a poem degraded as a participants' words are de-contextualized and re-contextualized in the poem?" The resolution to such questions usually involved thinking carefully upon my original research questions and interrogating myself about the purpose and intent of my research, trusting the expertise I possessed and my intimate understanding of participants and their context. Perhaps paradoxically, the more attentive I became to my research questions when met with the challenge of how to proceed, the more clearly I understood how to deal with questions like those above.

Aside from more practical challenges, ethical challenges also emerged in crafting found poems such as "The Hôte." As a White male researching the experience of others, some of different ethno-cultural backgrounds, I was alert to the concerns researchers such as Smith (1999) discuss regarding the potentially disempowering and colonizing nature of research. I could and needed to ask to what extent, even with the consent of participants who described themselves and identified as First Nations, did I have a right to re-arrange, edit and alter the sequence of the words of participants? An initial response to these concerns involved minimizing such activity. Maintaining a vigilance regarding the purpose of my research was also important, where I operated with the understanding that the use of participants' revelations was not a testing of the veracity, or questioning, of their experience, of the truth or meaningfulness of their thoughts and emotions, but remained a scrutiny of what Levinas and Derrida suggest concerning responsibility. By sharing their words more fully in the discussions that followed each found poem, and allowing their words to show the unique nature of each person, I safeguarded participants from being merely objects.

What also helped in being sensitive and attentive to concerns of misuse and misrepresentation of participants' words was my close association and familiarity with the participants borne in our many years of working together. While imperfect, such sensitivities were further informed through my involvement with First Nations communities and with having family of First Nations heritage. Ultimately, in fashioning found poems I attempted to let my participants' words stand on their own, avoiding any direct identification of persons or labeling of them as Aboriginal or nonAboriginal, female or male, or teacher or administrator. The discovery of these roles and identities I left to the reader. This resonated with a general goal with the use of found poetry and in my research in general, which was to provide insight into the 
shared human experience, such as the hôte, through the examples of individual's experience and words. While atypical perhaps, in avoiding the description and categorization of persons I hoped readers would focus on sensibilities and meanings resident in the words of people. In a manner similar to Levinas, and Kumashiro (2000), who suggest our identities are multiple and intersected and that no category or grouping is sufficient in defining people or ultimately understanding their experience, I chose to present participants' experience and words in a manner that did not position ethno-cultural realities as the central focus but their experience as human beings. My hope in this regard was to not just stand alongside participants, being with them as they related their experience, positioning their voices to be heard, but to "be-for" them, a state of togetherness that "is entered for the sake of safeguarding and defending the uniqueness of the Other" (Bauman, 1995, pp. 51-52).

\section{Concluding Thoughts}

While this article deals with crafting found poems, the challenge and process of crafting such poetry might in itself be considered an act of hospitality inhabited by all the uncertainty and tension of the hôte. Ruitbenberg (2005) suggests that hospitality exists not only "in the common and literal sense of a welcoming of flesh-and-blood guests and strangers, but also, in a more abstract and metaphorical sense, as a welcoming of intangible guests and strangers" (p. 15) who leave our identity "ajar" or in flux. In a way, as readers consider "The Hôte" they are engaging in a similar welcoming. Reading "The Hôte" is an invitation to consider the difference of others, to challenge what we know and how we think of ourselves. Here, even as the reader may focus on the experiences of identity, role and responsibility, identifying similarities with the experience of others, the poem provides a challenge to what the readers think of themselves, their situations and responsibilities. Despite my familiarity with this poem, this holds true for me as well.

However, if reading a poem is a hospitable act, perhaps the act of crafting a found poem is also a hospitable act, for the writer has invited in the presence and words of others, making a place for them and seeking to accommodate and deal with what they bring. In crafting the "The Hôte," and each time I read this poem, the faces of participants, their struggles, insights, challenges and triumphs visit me. Despite their presence as "intangible guests and strangers," they are not passive and quiet. Their presence and thoughts have dislodged and discomforted me and I realize while I have been crafting, believing I am the host and in control, I have been crafted, a 
guest in my own home, responding to the direction of guests. I find myself a guest in my own home, the guest-host, a hôte.

My efforts to secure insight and knowledge are productive yet remain uneasy and uncertain for the presence of these others, my participants, and their knowledge, while polite and well mannered, always push against and resist how I would craft and present their reality. The poem "The Hôte" is especially meaningful for me for the presence of others is alive within it; these people are in a struggle to find their way as educators but more importantly as human beings.

In crafting poems I realized my responsibility to these people has not ended, for their difference remains within me, affects me, and I am bound to them more tightly. While the crafting of poems allowed me to come to know participants more intimately, paradoxically, I also came to understand I will never know them, for even as I get comfortable in what I think I know about them, or what their experiences seem to reveal, dissonance and surprises emerge. I find the difference of others discomforts me and is beyond me. I find some comfort here, however, for acknowledging this paradox and accepting the uncertain and ambiguous nature of this situation leaves me, if we believe Levinas and Derrida, ethical. I understand that my responsibility to others such as my research participants lies not in unreflectively following research methods, but in attending to, accommodating and living with the uncertainty and confusion their arrival brings. In crafting poems such as "The Hôte," the difference of others teaches me that my responsibility as a researcher exists in opening "the way to the humanity of the human" (Derrida, 1999, p. 72), avoiding "the neutralization of the other who becomes a theme or object...reduction to the same" (Levinas, 1961, p. 43).

\section{Leaving the Discussion}

I have attempted to offer some insight into hospitality and the sensibility of the hôte as a way of conceiving of responsibility, and there is much to explore concerning this alternate understanding in educational contexts-explorations that can accomplished by examining the work of philosophers such as Levinas and Derrida most likely aided by others such as Bauman (1993, 1995), and Todd (2001, 2003a, 2003b, 2003c, 2007, 2008). 
In my use of found poetry, I believe that the creativity, artfulness and judgment involved in crafting poems made my work richer and more meaningful. The process of crafting poems and knowing they would foreground my discussions, motivated me and enlivened and informed other necessary tasks involved in interpretation. For me there was great value, utility and reward in found poetry and so, if my brief work here has prompted even a small spark of interest or a desire to learn more concerning found poetry or how an exploration of responsibility might emerge with their use, then I will count my efforts successful.

\section{References}

Bauman, Z. (1993). Postmodern Ethics. Oxford: Blackwell.

Bauman, Z. (1995). Life in Fragments: essays in postmodern morality. Oxford: Basil Blackwell.

Caputo, J. D. (1987). Radical Hermeneutics: Repitition, Desconstruction, and the Hermeneutic Project. Bloomington and Indianapolis: Indiana University Press.

Caputo, J. D. (2000). More radical hermeutics: On not knowing who we are. Bloomington and Indianapolis: Indiana University Press.

Davis, C. (1996). Levinas: An introduction. Cambridge: Polity Press.

Derrida, J. (1999). Adieu to Emmaneul Levinas (P.A. Brault \& M. Nass, Trans.). Stanford: Stanford University Press.

Derrida, J. (2002). Acts of Religion. New York: Routledge.

Eisner, E. (1991). The enlightened eye: qualitative inquiry and the enhancement of educational practice. New York: Macmillian Publishing.

Eisner, E., \& Peshkin, A. (1990). Qualitative inquiry in education : the continuing debate. New York: Teachers College Press.

Ellul, J. (1964). The Technological Society. New York: Vintage Books.

Gadamer, H. G. (1976). Philosophical hermeneutics. Berkeley: University of California Press.
Gadamer, H. G., \& Silverman, H. J. (1991). Gadamer and hermeneutics. New York ;: London : Routledge.

Hutchens, B. (2004). Levinas: A guide for the perplexed. London: Continuum.

Kumashiro, K. (2000). Toward a theory of antioppressive education. Review of Educational Research, 70(1), 25-53.

Leggo, C. (2006). Learning by Heart: A Poetics of Research. Journal of Curriculum Theorizing, Winter, 73-96.

Levinas, E. (1961). Totality and Infinity. Pittsburgh: Dusquense.

Levinas, E. (1981). Otherwise Than Being: Or Beyond Essence (A. Lingis, Trans.). Pittsburgh: Dusquense.

Molnar, T. (2009). Welcoming the Other: Understanding the Responsibility of Educators. Unpublished Dissertation, University of Victoria.

Richardson, L. (1994). Writing: A method of inquiry. In N. Denzin \& Y. Lincoln (Eds.), Handbook of Qualitative Research (pp. 516-529). Thousand Oaks: Sage.

Richardson, L. (2003). Poetic representation of interviews. In J. Gubrium \& J. Holstein (Eds.), Postmodern Interviewing (pp. 187-201). London: Sage Publications.

Ruitenberg, C. (2005). Leaving me ajar: Educating for hospitable identity. Unpublished Dissertation, Simon Fraser University. 
Smith, L. (1999). Decolonizing Methodologies: Research and Indigenous Peoples. New York: Zed Books.

Sparkes, A. (2002). Telling Tales in Sport and Physcial Activity: A Qualitative Journey. Champaign, IL: Human Kinetics.

Steffler, J. (1995). Language as matter. In T. Lilburn (Ed.), Poetry and knowing: Speculative essays \& interviews (pp. 45-51). Kingston, ON: Quarry Press.

Todd, S. (2001). 'Bringing more that I contain': ethics, curriculum and the pedagogical demand for altered egos. Journal of Curriculum Studies, 33(4), 431-450.

Todd, S. (2003a). A fine risk to be run? The ambiguity of eros and teacher responsibility. Studies in Philosophy and Education, 22(4), 31-44.
Todd, S. (2003b). Introduction: Levinas and education:The question of Implication. Studies in Philosophy and Education, 22(1), 1-4.

Todd, S. (2003c). Learning from the other: Levinas, pyschoanalysis, and ethical possibilities in education. Albany: State University of New York.

Todd, S. (2007). Teachers judging without scripts, or thinking cosmopolitan. Ethics and Education, 2(1), 25-38.

Todd, S. (2008). Welcoming and Difficult Learning: Reading Levinas with education. In D. Egea-Kuehne (Ed.), Levinas and Education: At the Intersection of Faith and Reason (pp. 171-185). New York: Routledge.

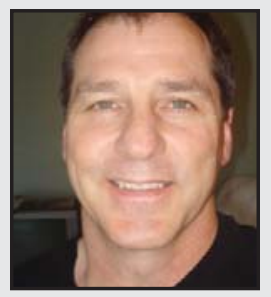

Tim Molnar is currently an assistant professor in the department of Curriculum and Instruction at the University of Saskatchewan. Prior to this he taught for over twenty years in a variety of contexts in public school systems from kindergarten to grade twelve. His teaching and research work involve the areas of science, teacher and technology education, curriculum theorizing and ethics. 